\title{
GUT MORPHOLOGY AND MORPHOMETRY IN THE EPAULETTED WAHLBERG'S FRUIT BAT (EPOMOPHORUS WAHLBERGI, SUNDEVALL, 1846)
}

\author{
A. N. Makanya, ${ }^{1,3 *}$ T. J. Self, ${ }^{2}$ C. N. Warui ${ }^{3}$ and D. K. Mwangi ${ }^{3}$ \\ ${ }^{1}$ Institute of Anatomy, University of Bern, Bühlstrasse 26, CH-3000 Bern 9, Switzerland, \\ ${ }^{2}$ Institute for Hearing Research, University of Nottingham, Nottingham NG7 2UH, United Kingdom, \\ ${ }^{3}$ Department of Veterinary Anatomy, University of Nairobi, P. O. Box 30197, Nairobi, Kenya
}

(Received: May 13, 1999; accepted: February 2, 2000)

\begin{abstract}
The morphological adaptations of the fruit bat small intestine to which the high functional efficiency could be related and the possible landmarks delineating the various parts of the gut were examined. The stomach was the carnivorous type with large rugae spanning the entire luminal aspect down to the pyloric sphincter, which was reflected internally as a prominent fold. Externally, the intestine was a continuous tube uninterrupted by any structures. The cranial fifth of the small gut had long, branching and anastomosing villi, which caudally turned to finger-like discrete structures that became rather short and stumpy and diminished at the beginning of the colon. The colon had longitudinal folds that were macroscopically discernible from the mucosal aspect of the opened intestine and that continued into the rectum. The small gut formed $94 \%$ of the whole intestinal length, the colon and the rectum taking 4 and $2 \%$, respectively. Ultrastructurally, the enterocyte showed a prominent brush border and the lateral membranes were modified into numerous tortuous interdigitating processes. Adjacent enterocytes were joined by these processes through desmosomes. The processes also participated in pinocytotic fluid uptake from the intercellular spaces with resultant numerous intracellular vacuoles of varied sizes. Solutes absorbed into the cells were probably first passed into the intercellular compartment to create a concentration gradient thus enhancing further absorption into the cell. We conclude that the uniquely elaborate ultrastructure of the enteric epithelium coupled with the vast microvillous surface areas reported elsewhere are partly responsible for the very high absorption rates reported in the fruit bat small intestine.
\end{abstract}

Keywords: Fruit bat - gut - landmarks - epithelium - ultrastructure

\section{INTRODUCTION}

The remarkably high functional efficiency of the fruit bat small intestine has been attributed in part to high absorptive microvillous surface areas [21, 29, 30]. Although the morphology of the fruit bat gastrointestinal tract (GIT) has received considerable attention over the years, there has been little emphasis on the qualitative adaptations to which such a remarkable performance could be ascribed. Though there is consensus that a caecum and an appendix are not parts of the chiropteran GIT, macroscopic identification and delineation of the various parts of the GIT of the fruit bat for various studies (say, stereology, physiology etc.) [27], may be difficult. Externally the

*Corresponding author; E-mail: makanya@ana.unibe.ch 
small and large intestine merge undramatically $[16,26,39,49,50]$. Previously we have indicated that such boundaries may be approximated on the account of the changing diameter [27, 28] while Okon [40] indicated that the various parts present could be identified histologically. The latter method, however, is inapplicable in most other non-histological studies. The complexity of gut morphology is related to type of diet $[7,46,48,57]$ and a number of reports also indicate that there are taxonomic inclinations $[7,57]$.

In bats, digestion occurs very fast and the passage of food through the GIT has been shown to be rapid $(18,23,25,36,49,50,56]$ while absorption of sugars is three to four times faster than in the rat intestine [19]. Reports on the fine structure of chiropteran intestine have paid little attention to cellular and subcellular details (e.g. [16, 50] except the observation by Manley and Williams [31] that absorptive vacuoles were frequent in the enterocytes. In our recent studies, intestinal microvillous surface areas in E. wahlbergi were found to be up to 18 times greater than in the rat [30]. The current study uses the light and transmission electron microscopes in an attempt to explain the histological and ultrastuctural morphological adaptations responsible for the high digestive and absorptive capacities of the intestine of the chiropteran frugivore.

\section{MATERIALS AND METHODS}

\section{Bat provenance}

The qualitative investigation used only two animals, one for the transmission electron microscopy and one for the light microscopy studies. Gross morphometric estimates on the intestinal components were done on five specimens used in previous studies [29, 30].

Capture methods were as outlined in these previous studies. Briefly, bats captured by mist-netting were transported to the laboratory in cages, weighed and then killed by intraperitoneal injection of sodium pentobarbitone at a dosage of $50 \mathrm{mg} \mathrm{kg}^{-1}$ body weight. The abdominal cavity was opened through a ventromedian incision to reveal the abdominal viscera which were studied in situ. Subsequently the oesophagus was severed immediately cranial to the diaphragm. The pelvic bones were carefully cut to reveal the rectum and then the entire gastrointestinal tract was dissected out by tearing off the mesenteries and immediately transferred to a bath of $0.85 \%$ sodium chloride. The intestinal tract was opened by a longitudinal incision along the mesenteric border, ingesta/digesta washed off with fresh saline. Subsequently lengths of the segments (small intestine, colon and rectum) were obtained by direct measurement under slight stretch using a ruler. The small intestine was separated out and immersed into a solution of $2.5 \%$ phosphate buffered glutaraldehyde $(350 \mathrm{mOsm}, \mathrm{pH} 7.3)$ for at least 24 hours. The samples for morphometry were treated as outlined elsewhere $[29,30]$ while the ones for qualitative morphology were dealt with as detailed below. 


\section{Light Microscopy (LM)}

Small intestinal segments (about $2 \mathrm{~cm}$ long) of the fixed intestine were obtained from five approximately equidistant positions along the small intestinal length starting with the most cranial part and ending with the most posterior part. The segments were dehydrated in ascending concentrations of ethanol and then embedded in methyl methacrylate resin. Sections were obtained at a nominal thickness of $3 \mu \mathrm{m}$ using a Heidelberg HM 350 Microtome and subsequently stained with Hematoxylin and Eosin (H\&E). Sections were photographed using Olympus Vanox S Light Microscope.

\section{Transmission Electron Microscopy (TEM)}

Segments were sampled from five approximately equidistant positions from the entire length of the small intestine as described under LM. The segments were diced, washed in $0.1 \mathrm{M}$ phosphate buffer $(\mathrm{pH} 7.3)$, postfixed in $1 \%$ osmium tetroxide and then dehydrated through ascending concentrations of acetone starting from $20 \%$ through $40 \%, 60 \%, 80 \%, 90 \%$, two changes of $100 \%$ and finally infiltrated with and embedded in Transmit resin (Taab, UK). Ultra-thin sections were obtained at $90 \mathrm{~nm}$ by use of a Reichert-Jung (Austria) ultramicrotome. These were stained with uranyl acetate in the dark, counterstained with lead citrate in presence of sodium hydroxide and viewed on a Philips EM 300 or a Philips EM 410 electron microscope at an accelerating voltage of $80 \mathrm{kv}$.

\section{Morphometry}

Macroscopic morphometry was performed as described above. Ultrastructurally, parameters of the microvilli were estimated to demonstrate that the intestines used in the study were from healthy adult individuals (see, for example, 2, 3, 5, 12). Microvillous lengths were obtained from micrographs printed at a final magnification of $\times 10700$ by measuring the actual lengths of ten microvilli per micrograph (Fig. 14) and obtaining the average for the whole intestine. The distance between microvilli, microvillous diameters and microvillous packing densities were estimated from cross-sectional profiles of the microvilli at a final magnification of $\times 36000$ (Fig. 15). Microvillous packing densities were estimated by placing a grid with a systematic set of random windows of known area (Fig. 15) on micrographs with transected microvilli and counting the number of microvilli per unit area. The squares were equipped with a rejection line for ease of counting (e.g. Gundersen [15]). The surface area of the average microvillus, $\mathrm{s}(\mathrm{mv})$, was estimated by multiplying the product of the mean diameter $(\mathrm{d})$ and the mean length (1) by pi $(\pi)$. Thus, $\mathrm{s}(\mathrm{mv})=$ $\pi$ ld. Surface area increases due to microvilli (surface amplification) was estimated as the ratio of the microvillous packing density to the surface area of the average microvillus [34]. Detailed stereological analyses are available elsewhere [29, 30]. 

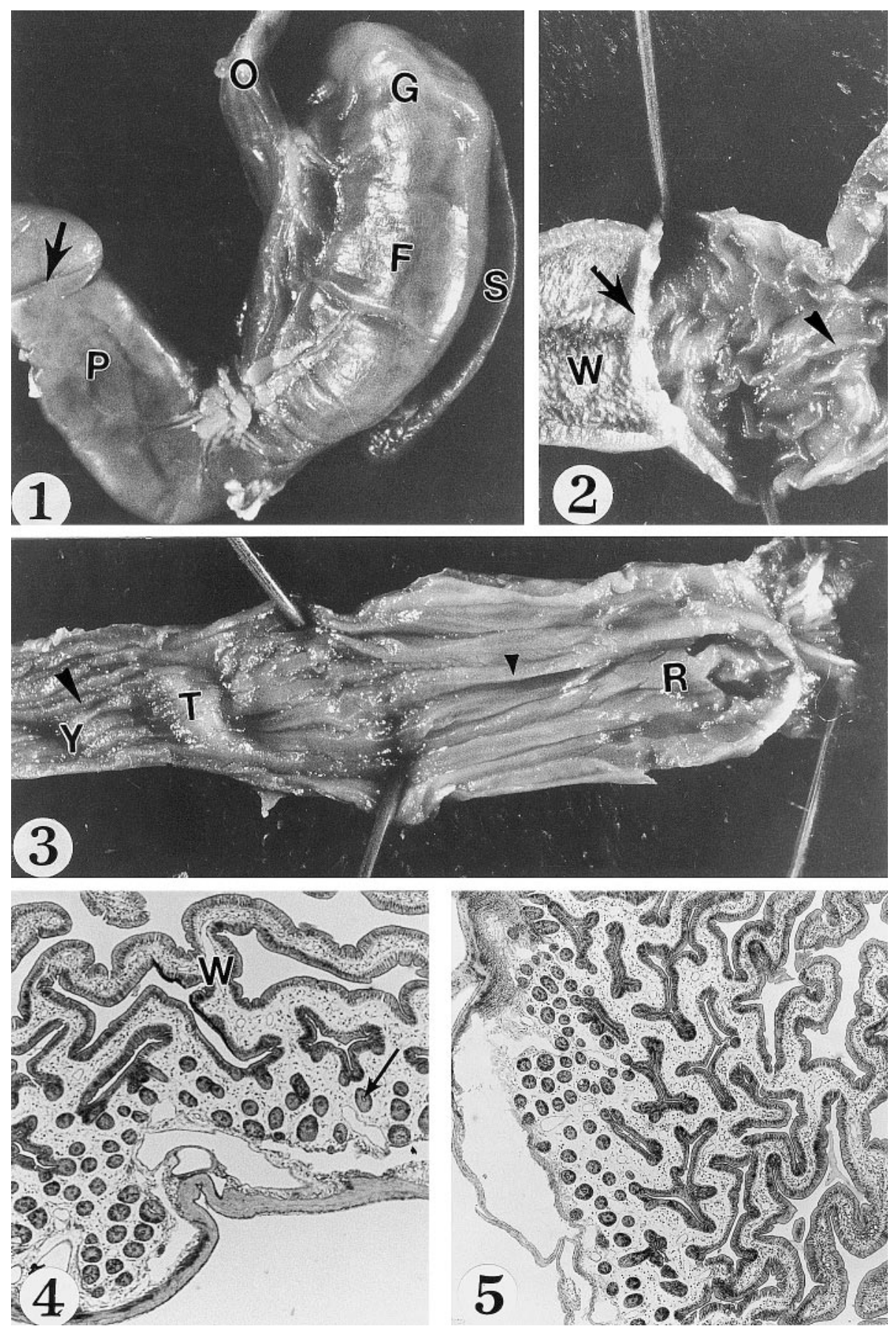


\section{RESULTS}

The fruit bat stomach was roughly U-shaped and elongate with a large cardiac caecum, a large fundus and a long pylorus (Fig. 1). The pyloro-intestinal junction was marked by a prominent groove externally (Fig. 1) and by a big fold luminally (Fig. 2). Grossly, the gastric mucosa was thrown into longitudinal rugae that extended down to the pylorus and ceased abruptly at the very prominent transverse fold that marked the pyrolic sphincter (Fig. 2).

The intestine was an almost uniform tube with the proximal part showing a slightly greater diameter and the small intestine inconspicuously gave way to a short colon which, farther caudally, gave way to an even shorter but broader rectum (Fig. 3). An appendix and a caecum were absent and, externally, the beginning of the colon was not unequivocally identifiable, safe for a slight increase in diameter. On the mucosal surface of the opened intestine, however, there were macroscopically recognisable changes. The cranial part of the intestine was characterised by large, grossly visible papillae-like villi (Fig. 2) which diminished in size caudally and towards the posterior fifth of the intestine gave way to the longitudinal folds of the colon. The latter extended distally to the rectum becoming less conspicuous towards the anus.

The mucosa of the cranial $20 \%$ of the small intestine of the fruit bat was characterised by long-branching and anastomosing villi (Figs 4, 5). The height of the villi and degree of branching and anastomoses decreased gradually in a cranio-caudal direction (Figs 6,7) giving way to tall finger-like or tongue-like villi in mid-intestine (Fig. 8) and farther caudally, to short, rather stumpy structures (Fig. 9). There was no definite demarcation between the colon and the rectum safe for a remarkable increase in diameter and the longitudinal folds in the latter were larger. The histological structure of the fruit bat intestinal wall was fundamentally similar to that of the terrestrial mammals (Fig. 8) but in the cranial areas, especially where there were villous anastomoses, the submucosa was thicker and cryptal glands of Lieberkuhn were notably more abundant (Figs 4-9).

Fig. 1. Photograph showing the stomach and the cranial part of the intestine of the epauletted fruit bat, Epomophorus wahlbergi. The oesophagus $(\mathrm{O})$, the cardiac caecum $(\mathrm{G})$, the fundus $(\mathrm{F})$ and the Pylorus $(\mathrm{P})$ are shown. The pyloro-intestinal junction is marked by an external groove (arrow) and the spleen, (S) is seen on the greater curvature of the stomach $(\times 4)$. Fig. 2. A photograph of the pylorus and the cranial part of the small intestine of the epauletted fruit bat. The intestine and pylorus have been opened to show the pyloric rugae (arrow head), the pyloric sphincter (arrow) and the papillae-like villi (W) ( $\times 4)$. Fig. 3 . Photograph of the posterior part of the intestine of the fruit bat showing the colon $(\mathrm{Y})$ and the rectum $(\mathrm{R})$. Note that the boundary between the rectum and the colon (T) is marked by an increase in circumference of the former. Longitudinal folds (arrowheads) are evident in both the colon and the rectum $(\times 4)$. Fig. 4 . A LM picture showing a section from the cranial one fifth of the intestine of fruit bat showing the anastomosing and branching villi (W). At this level there are several layers of cryptal glands (arrow) in the submucosa $(\times 40)$. Fig. 5. A LM picture of a section of the intestine taken very close to the pyloric sphincter showing extensive villous branching and anastomoses forming a network-like pattern $(\times 40)$ 
A. N. MaKanYA et al.
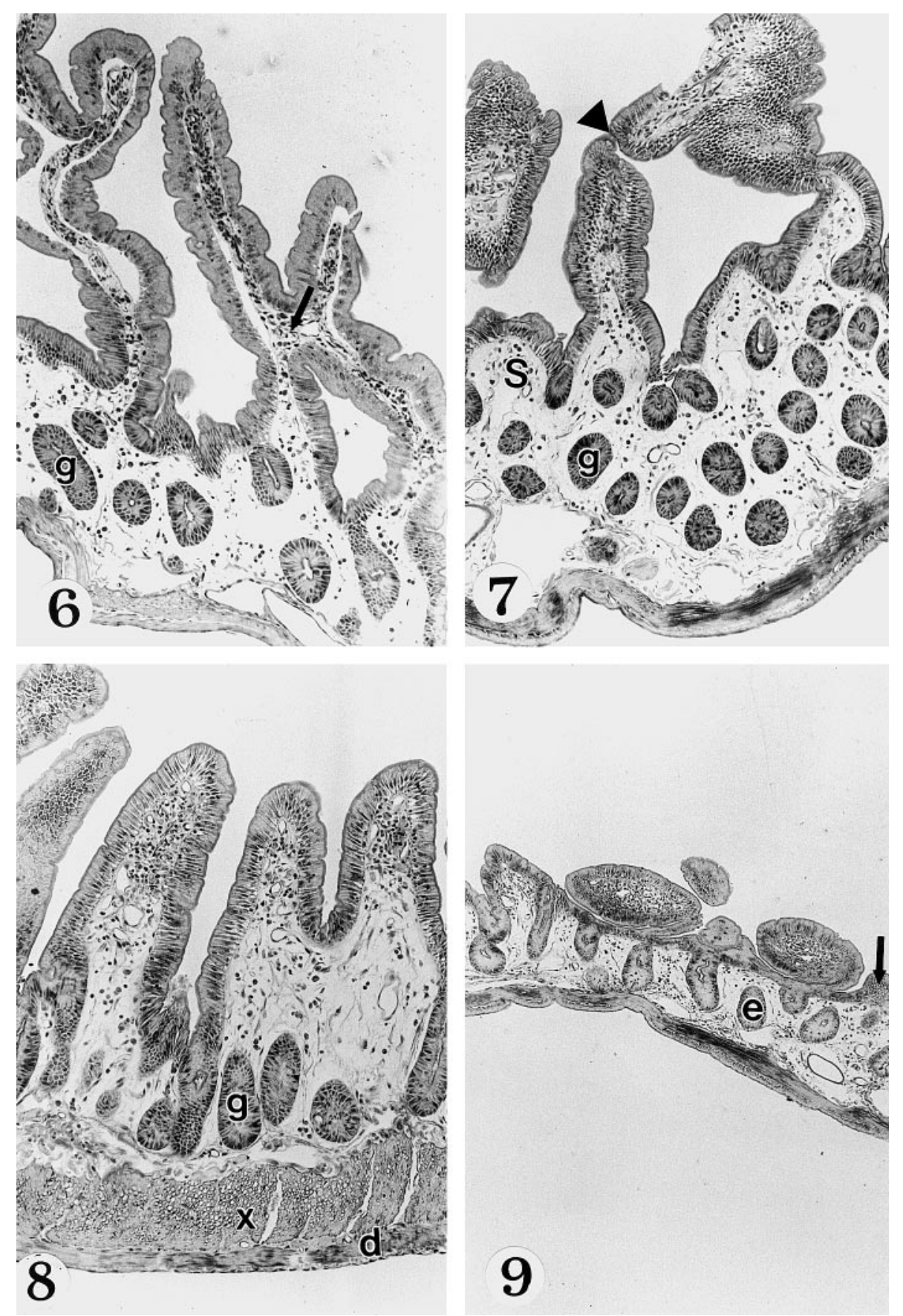

Acta Biologica Hungarica 52, 2001 

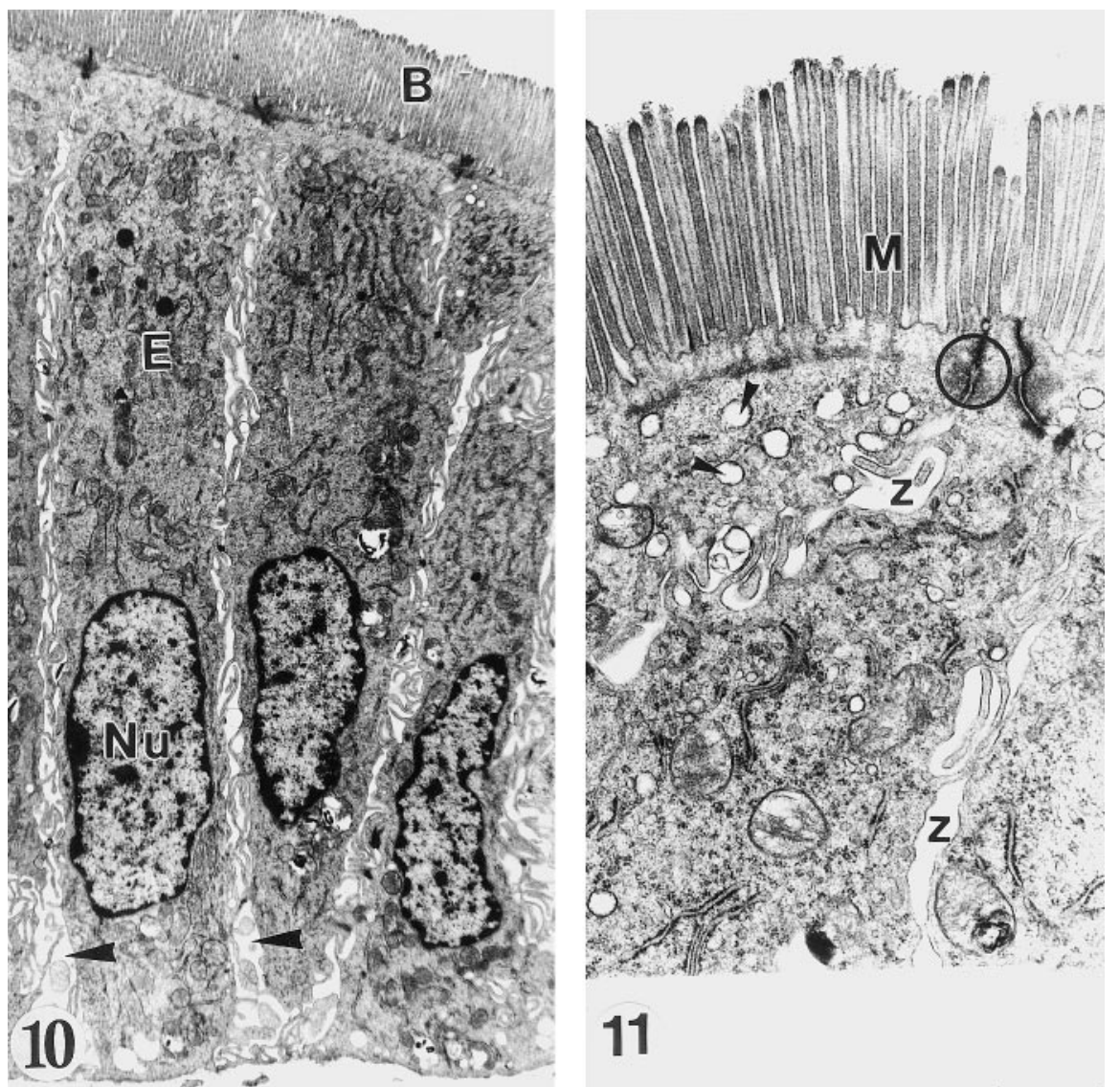

Fig. 10. An electron micrograph of the enteric epithelium in the bat showing an enterocyte (E) with a prominent brush border (B), and enlarged intercellular spaces (arrowheads). The ovoid nuclei (Nu) occupy the lower third of the enterocyte $(\times 4875)$. Fig. 11. An electron micrograph showing the apical part of an enterocyte with prominent microvilli (M), apical junctional complex (encircled) and an enlarged intercellular space (z). The tiny apical vesicles (arrowheads) probably contain absorbed materials $(\times 18500)$

Fig. 6. Villous branching and anastomoses decrease as one progresses caudally and are restricted to the upper parts of the villi. The villous core tissue and the epithelium are continuous in the adjoining villi (arrow). Several layers of crypts (g) are evident but are less numerous than in the preceding segments $(\times 100)$. Fig. 7. Towards the middle of the intestine, villous branching and anastomoses are few, appear incomplete (arrowhead) and the shapes of villi are a bit irregular. The submucosal tissue (S) is abundant and contains numerous crypts $(\mathrm{g})(\times 100)$. Fig. 8 . A LM picture showing a longitudinal section from the middle of the intestine of fruit bat. From this level up to the beginning of the colon, villous anastomoses and branching are absent. The muscle layers, inner circular $(\mathrm{X})$ and outer longitudinal (d) are demonstrated. The crypts $(\mathrm{g})$ at this level are also fewer and are in one layer $(\times 125)$. Fig. 9. A LM picture showing a section from the most posterior part of the small intestine of the fruit bat. Villi have diminished into stumpy structures (arrow), the crypts (e) are few and the intestinal wall is relatively thinner. $(\times 100)$ 

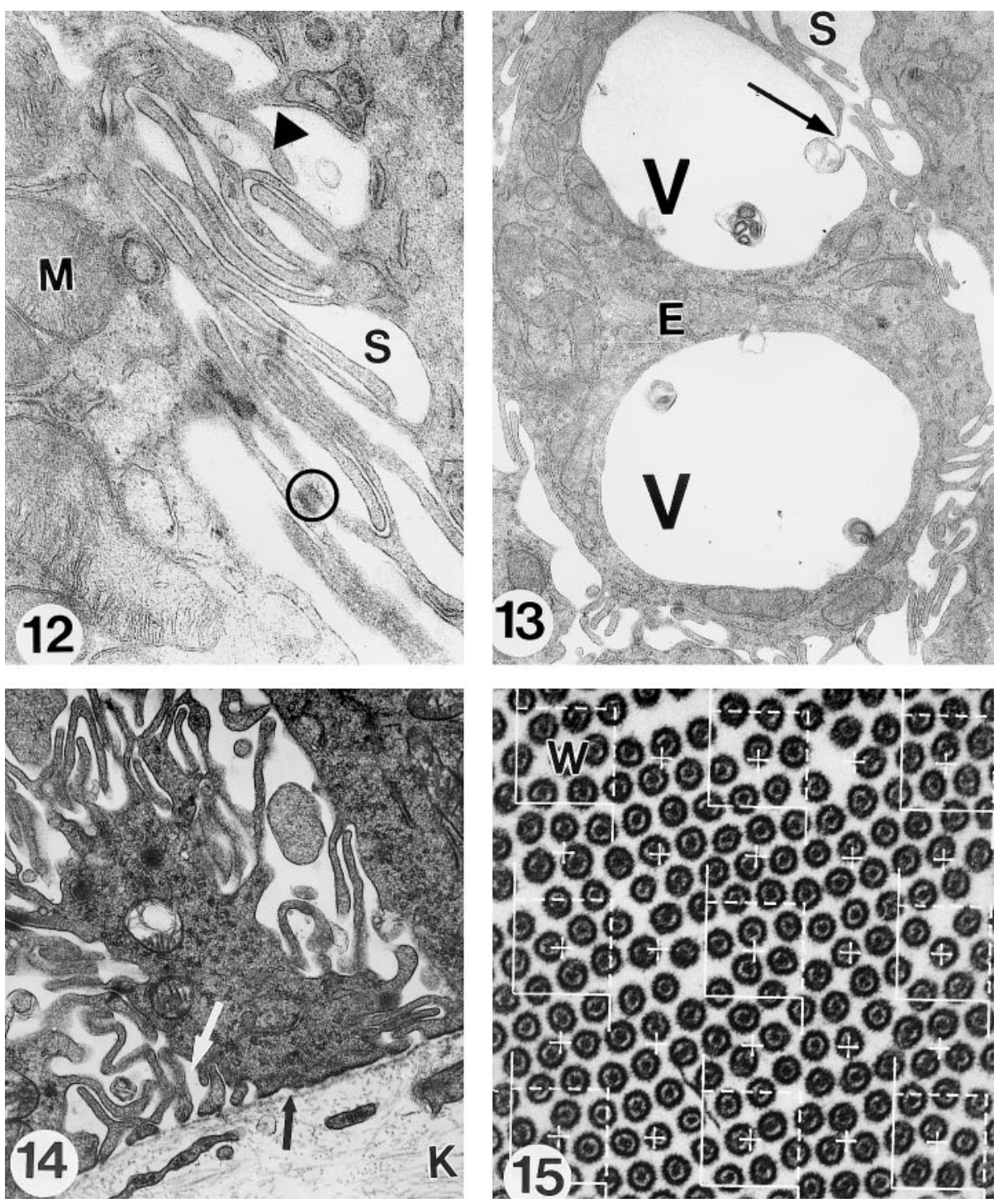

Fig. 12. An electron micrograph showing the enlarged intercellular spaces (S) and numerous long and tortuous cytoplasmic processes (arrowhead). Note the very prominent desmosomes (encircled) formed between apposing processes of the two adjacent cells. Numerous mitochondria (M) are also evident in the neighbourhood $(\times 23$ 130). Fig. 13. An electron micrograph showing enterocytes (E) transected at the supranuclear level showing enlarged vacuoles (V). The cytoplamsic processes show a tendency to take in fluid from the intercellular space (S) into the vacuole (arrow) (×9430). Fig. 14. An electron micrograph showing the basal aspect of the enterocytes with enlarged intercellular spaces (white arrow). The cells rest on a thin basal lamina (black arrow) which forms the only barrier between the intercellular spaces and the villous core connective tissue $(\mathrm{K})(\times 11560)$. Fig. 15. An electron micrograph showing transected microvilli in the intestine of the fruit bat. These microvilli measure about $110 \mathrm{~nm}$ in diameter on average and have a mean packing density of 52.7 to a square micron. The counting windows (W) preesented here have an actual side length of $0.36 \mu \mathrm{m}(\times 32360)$

Acta Biologica Hungarica 52, 2001 
Ultrastructurally, the enteric epithelium was simple columnar, just like in other mammals but the inherent cellular modifications were remarkable. The enterocytes had numerous vacuoles and enlarged intercellular spaces (Figs 10-12). The enterocyte lateral membranes were modified into long and tortuous cytoplasmic processes that ramified the rather spacious intercellular spaces (Figs 10-13). There were numerous mitochondria and the rough endoplasmic reticulum were well developed (Figs 10, 12).

The mean body weight of the fruit bat was $89 \pm 17.2 \mathrm{~g}$, the fore gut had a length of $808 \pm 121.2 \mathrm{~mm}(94 \%)$ while the colon and rectum measured $37.7 \pm 16.7(4 \%)$ and $22.2 \pm 6.2 \mathrm{~mm} \mathrm{(2 \% )} \mathrm{in} \mathrm{length,} \mathrm{respectively} \mathrm{(Table} \mathrm{1).} \mathrm{The} \mathrm{enterocyte} \mathrm{microvilli}$ had a mean length of $2.53 \pm 0.47 \mu \mathrm{m}$ (Fig. 15), mean diameter of $110 \pm 2.3 \mathrm{~nm}$ (Fig. 15 ) and were packed $51 \pm 9.94$ to a $\mu \mathrm{m}^{2}$. The surface area of the average microvillus was estimated to be $0.99 \pm 0.02 \mu \mathrm{m}^{2}$ and the microvilli were spaced at $0.05 \pm 0.005$ $\mu \mathrm{m}$. The surface area increase due to microvilli was estimated at 51.5. These details are provided in Table 2 below.

Table 1

Gender, body weights (grams) and the dimensions $(\mathrm{mm})$ of the various components of the intestine in the fruit bat, E. wahlbergi

\begin{tabular}{ccccccc}
\hline & & & \multicolumn{3}{c}{ Intestinal lengths $(\mathrm{mm})$} \\
\cline { 4 - 6 } Bat No. & Sex & $\begin{array}{c}\text { Body } \\
\text { weight }(\mathrm{g})\end{array}$ & fore gut & colon & rectum & total \\
\hline \multirow{2}{*}{1} & male & 100 & 890 & 50 & 25 & 965 \\
2 & female & 69 & 645 & 25 & 19 & 689 \\
3 & male & 113 & 995 & 65 & 32 & 1092 \\
4 & female & 96 & 790 & 35 & 24 & 849 \\
5 & male & 71 & 742 & 23 & 14 & 793 \\
6 & male & 87 & 786 & 28 & 19 & 793 \\
\hline Mean & & 89 & 808 & 37.7 & 22.2 & 863.5 \\
SD & & $(17.2)$ & $(121.2)$ & $(16.6)$ & $(6.2)$ & $(143.6)$ \\
\hline
\end{tabular}

\section{DISCUSSION}

From this study, it is clear that the small and large intestine of the fruit bat are macroscopically identifiable externally, though less precisely on the account of the changing diameter and unambiguously from the mucosal surface topography on the basis of the very characteristic longitudinal folds. Generally, the complexity of gut morphology relates to taxonomy and diet type $[7,48]$. Enlarged hindguts serve as microbial fermentation vats in herbivores [22, 57]. Specifically, the colon is the site for water, electrolyte and short chain fatty acid absorption. In non-fermenting animals such as carnivores and insectivores, the caecum is very simple or absent while in her- 
bivores it acts as a fermentative chamber [57]. Foods consumed by fruit bats generally contain large amounts of water [4] estimated at 70-90\% [1]. Further, bats have been seen to ingest leaves and whole flowers or parts thereof $[6,9,14,19,31,37,42$, $43,52,53$ ] presumably to augment nitrogen deficiencies in their diet [55]. However, an appreciable fermentative activity in the bat gut is doubtful since only the juices are swallowed and fibrous ingredients are rejected [33]. The ingestion of such components with fruit may, in many instances be accidental [33]. This fact is gaining more credence since fruit bats have been shown to meet their nitrogen requirements on natural unsupplemented fruit diet $[10,24]$, indeed even without having to overingest energy [10]. Shilton et al. [45] report retention of food in the gut of frugivores for up to 12 hours and hypothesise that this allows increased nutrient assimilation. The hindgut in the fruit bat as such may be of no appreciable fermentative value but its role in water and electrolyte absorption is imperative. The colon may also participate in digestion and absorption of nutrients since digestive enzymes are also present [38].

The fruit bat has achieved high intestinal functional capacities by having long, branching and anastomosing villi and long, densely packed microvilli, which interpret into high absorptive surface areas [30], augmented by the elaborate structure of

Table 2

The microvillous dimensions in the fruit bat, E. wahlbergi, estimated here compared with those from a previous study and with those of another fruit bat, Rousettus aegypticus and those of the laboratory rat, Rattus norvegicus

\begin{tabular}{|c|c|c|c|c|}
\hline \multirow{2}{*}{ Parameter } & \multicolumn{4}{|c|}{ Animal species } \\
\hline & ${ }^{*}$ E. wahlbergi & ${ }^{* *} E$. wahlbergi & ***R. aegypticus & ***R. norvegicus \\
\hline $\begin{array}{l}\text { Microvillous } \\
\text { length }(\mu \mathrm{m})\end{array}$ & $2.54 \pm 0.47$ & $\begin{array}{c}2.79 \\
(11.6 \%)\end{array}$ & $23.6 \pm 1.0$ & $1.14 \pm 0.2$ \\
\hline $\begin{array}{l}\text { Microvillous } \\
\text { diameter }(\mu \mathrm{m})\end{array}$ & $0.11 \pm 0.02$ & $\begin{array}{c}0.094 \\
(8.3 \%)\end{array}$ & $0.099 \pm 0.01$ & $0.14 \pm 0.01$ \\
\hline $\begin{array}{l}\text { Microvillous } \\
\text { surface area } \\
\left(\mu \mathrm{m}^{2}\right)\end{array}$ & $0.99 \pm 0.02$ & $\begin{array}{c}0.83 \\
(11.7 \%)\end{array}$ & $1.0 \pm-$ & $0.5 \pm-$ \\
\hline $\begin{array}{l}\text { Microvillous } \\
\text { spacing }(\mu \mathrm{m})\end{array}$ & $0.05 \pm 0.005$ & - & $0.043 \pm 0,005$ & $0.038 \pm 0.001$ \\
\hline $\begin{array}{l}\text { Microvillous } \\
\text { packing density } \\
\left(\mathrm{No} . / \mu \mathrm{m}^{2}\right)\end{array}$ & $51.0 \pm 9.94$ & $\begin{array}{c}61.4 \\
(20.0 \%)\end{array}$ & $57.0 \pm 2.70$ & $36.0 \pm 3.70$ \\
\hline $\begin{array}{l}\text { Surface amplifica- } \\
\text { tion factor }\end{array}$ & 51.5 & $\begin{array}{c}50.0 \\
(6.1 \%)\end{array}$ & 57.0 & 18.0 \\
\hline
\end{tabular}

Sources of data: *This study; **Makanya et al. [30]; ***Keegan and Mödinger [21].

Figures are given as mean + SD or mean (cv \%). See Makanya et al. [30] for a complete stereological analysis of the intestinal surfaces. 
the enterocytes described here. The enterocytes were unique in that they possessed large intracellular vacuoles and their lateral membranes were modified into elaborate, long and tortuous interdigitating cytoplasmic processes. Save for a brief mention of the presence of "absorption vacuoles" in the fruit bat enterocytes by Manley and Williams [31] based on light microscope sections, enterocyte vacuolation is either considered neotenic or pathological. Such vacuoles occur in the newborn mammalian enterocytes when the animal is absorbing immunoglobulin macromolecules (e.g. [2, 3]). In pathological situations, enterocyte vacuolation is encountered in microvillous inclusion disease [5] and in ethanol toxicity [12]. However, our morphometric estimates prove that our results were based on normal adult animals since they compare closely with those reported elsewhere [21,30], (Table 2). Similar vacuoles are encountered in the highly absorptive normal kidney proximal tubule epithelium. The latter, however, are different in that they are somewhat smaller in size, have a clear lysosomal origin and are mainly apical in location (e.g. [41, 51]). Conversely, the vacuoles encountered in the bat intestine were rare in the apical cytoplasm, were large and had their origin from the lateral cell membranes through the participation of the cytoplasmic processes (Fig. 12). The putative functions of these processes were quadripartite in that: 1 . they helped to reinforce the architecture of the rather large intercellular spaces; 2. formed cell to cell junctions (desmosomes), (Figs $12,13) ; 3$. were involved in pinocytotic admittance of intercellular fluid into the enterocytes resulting in the large vacuoles (Fig. 12) and; 4. amplified the surface areas of the lateral cell membranes.

The mechanisms involved in the transfer of nutrients, water and electrolytes from the intestinal lumen to the blood stream in the bat have not been studied but may be assumed to conform to those of the other mammalian species. In mammals, the apical enterocyte membrane is equipped with digestive enzymes and transporter proteins, which are involved in the digestion and absorption of proteins and carbohydrates [13] while the basolateral membranes contain $\mathrm{Na}^{+} / \mathrm{K}^{+}$-ATpase. The latter actively transports sodium from the cell across the lateral membranes and into the intercellular spaces where it creates a standing gradient that draws water [13] and solutes $[35,47]$ through the epithelium and into intercellular spaces and finally into the capillaries. Fatty acid absorption occurs by non-energy expendient passive diffusion and after reconstitution into triglycerides, they are passed into the intercellular compartment and finally into bloodstream via lymphatics [13]. It is thus imperative that the lateral cytoplasmic processes in the bat play a role in the transfer of materials from the absorptive cell to the intercellular spaces and possibly any subsequent exchange between these two compartments.

Though there is morphological evidence for pinocytosis, the materials transferred and the precise sequence of events remain unknown. A hypothesis is put forward to explain the possible events that take place: that sodium coupled transport of sugars from the intestinal lumen draws water with it into the cytosol. $\mathrm{The}^{+} / \mathrm{K}^{+}$-ATpase in the basolateral membranes then draws sodium into the intercellular spaces followed by solutes. This would result in a high concentration gradient in the absorptive cell allowing further osmotic absorption of solutes from the intestinal lumen with the 
resultant rapid absorption rates reported by Keegan [19]. It has indeed been shown that glucose transport is coupled with the energy dependent sodium symport [58] and that the intercellular spaces in the enteric epithelium are important in electrolyte and water absorption [13, 44]. Keegan [20] indicated that there was no active absorption of glucose in the bat intestine based only on estimations of concentrations of the luminal glucose and the reabsorbate. However, lack of energy expenditure during glucose absorption in the latter study was not unequivocally demonstrated and the preponderance of mitochondria in the absorptive cells (Fig. 13) implicates energy expenditure. Further, the surface of lateral membranes is greatly amplified by the cytoplasmic processes and the intercellular clefts are enlarged, a strong pointer towards facilitated diffusion of water into the intercellular clefts. The contribution of paracellular fluid absorption to the swelling of the intercellular clefts, however, cannot be ruled out since passage of materials has been shown to occur through the cell tight junctions [11, 40, 47].

Results in this and other studies $[21,29,30]$ show that the microvilli in the fruit bat intestine are long with subsequent large microvillous surface areas. An expansive microvillous surface area promotes intestinal activity in three ways: 1.) increases surface through which nutrients can be absorbed, 2.) avails more membrane borne digestive enzymes and 3.) provides a greater surface for digestive activity to take place. It has been shown that the brush border itself is an important site of digestive activity [32]. This is because the brush border contains some of the important digestive enzymes either in the plasma membrane or adsorbed to the latter [8] and also contains carrier proteins believed to be involved in absorption of nutrients [35].

This study has attempted to unravel some of the intricacies involved in the functional design of the fruit bat small intestine. Our results here reinforce some previous observations that the evolution of gut morphology in the bat has been aimed at reducing bulk [57] and perhaps also decreasing gut transit times and having an extremely high digestive and absorptive capacities. Concise interpretation of the functional morphology of the fruit bat small intestine, however, remains complex unless physiological and other studies are conducted to understand the sequence of events during absorption. This is further complicated by the fact that mechanisms involved in fluid transport by epithelia remain poorly understood [47]. The fruit bat intestine would probably form an interesting model for such studies since there are fewer goblet cells and thus the epithelium looks less heterogeneous (see for example, [47]). Stereological estimates of cell sizes [17], numbers and also studies on enteric enzymes and glucose transporters may further elucidate the remarkable functional capacity of the chiropteran intestine.

\section{ACKNOWLEDGEMENTS}

We acknowledge financial support from the World Bank, the Deans' Committee of the University Of Nairobi Grant No. 500-655-375 and the German Academic Exchange (DAAD) grant No. 500-662-006. We thank Messrs JM Gachoka, Barry Shaw, Beat Haenni and Alan Pyper for their technical assistance and Mr Issa Aggundey for assistance in the procurement of bats. 


\section{REFERENCES}

1. Altman, P. L., Dittmer, D. S. (1968) Metabolism. Fed. Am. Soc. Exp. Biol., Bethseda, Maryland, 737 pp.

2. Asari, M., Kawaguchi, N., Wakui, S., Fukaya, K., Kano, Y. (1987) Development of the bovine ileal mucosa. Acta Anat. 129, 315-324.

3. Asari, M., Sasaki, K., Igarashi, S., Amasaki, T., Moriya, H., Amasaki, H. (1991) Developmental changes in the ferret ileum during the postnatal period. Okajimas Folia Anat. Jpn. 68, 1-6.

4. Bassett, E. J., Studier, E. H. (1988) Methods of determining water balance in bats. In: Kunz, T. H. (ed.) Ecological and behavioural methods for the study of bats. Smithsonian Institution Press, Washington DC, pp. 1-28.

5. Bell, W. S., Kerner, J. A. Jr, Sibley, R. K. (1991) Microvillous inclusion disease. Am. J. Surg. Pathol. $15,1157-1164$.

6. Cheke, A. S., Dahl, J. F. (1981) The status of bats on Western Indian Ocean islands with special reference to Pteropus. Mammalia 45, 205-238.

7. Chivers, D. J., Hladik, C. M. (1980) Morphology of the gastrointestinal tract in primates: comparisons with other mammals in relation to diet. J. Morphol. 166, 337-386.

8. Crane, R. K. (1960) Intestinal absorption of sugars. Physiol. Rev. 40, 789-825.

9. Cunningham van Someran, R. (1972) Some fruit bats eat leaves. Bull. East Afr. Nat. Hist. Soc. 1972.

10. Delorme, M., Thomas, D. W. (1996) Nitrogen and energy requirements of the short tailed fruit bat (Corilla perspicillata): fruit bats are not nitrogen constrained. J. Comp. Physiol. B 166, 427-434.

11. Erlij, D., Palomo, A. M. (1978) Role of tight junctions in epithelial function. In: Giebisch, G., Tosteson, D. C., Ussing, H. H. (eds) Membrane transport in biology, Vol. III. Springer Verlag, Berlin, pp. 27-55.

12. Estrada, G., Antonio del Rio, J., Garcia-Valero, J., Lopez-Tejero, M. D. (1996) Ethanol in utero induces epithelial damage and altered kinetics in the developing rat intestine. Teratology 54, 245-254.

13. Fawcett, D. W. (1994) Intestines. In: Fawcett, D. W. (ed.) Bloom and Fawcett: - A textbook of histology, 12th edn. Chapman and Hall, New York, pp. 617-651.

14. Funmilayo, O. (1976) Diet and roosting damage and environmental pollution by the straw coloured fruit bat in south-western Nigeria. Niger. Fld. 41, 136-142.

15. Gundersen, H. J. G. (1977) Notes on the estimation of the numerical density of arbitrary profiles: the edge effect. J. Microsc. 111, 219-223.

16. Ishikawa, O. K., Matoba, M., Tanaka, H., Ono, K. (1985) Anatomical study of the intestine of the insect-feeder bat Myotis frater kaguae. J. Anat. 142, 141-150.

17. Karlsson, L. M., Makanya, A. N. (1999) Stereological estimation of size-weighted enterocyte mean size in the bat intestine. Acta Steriol. 18, 39-47

18. Keegan, D. J. (1975) Aspects of absorption of fructose in Rousettus aegypticus. S. Afr. J. Med. Sci. 40, 49-55.

19. Keegan, D. J. (1977) Aspects of assimilation of sugars by Rousettus aegypticus. Comp. Biochem. Physiol. 58A, 349-352.

20. Keegan, D. J. (1980) The lack of active glucose transport system in the bat intestine. S. Afr. J. Sci. 76, $570-571$.

21. Keegan, D. J., Mödinger, R. (1979) Microvilli of the intestinal mucosal cells of Rousettus aegypticus. S. Afr. J Zool. 14, 220-223.

22. Kerlins, P., Phillips, S. (1983) Absorption and secretion of electrolytes by the human colon. In: Bustos-Fernandez, L. (ed.) Colon structure and function. Plenum, New York, pp. 17-44.

23. Klite, P. D. (1965) Intestinal bacterial flora and food transit times in three neotropical bat species. $J$ Bacteriol. 90, 375-379.

24. Korine, C., Arad, Z., Arieli, A. (1996) Nitrogen and energy balance of the fruit bat Rousettus aegypticus, on natural fruit diets. Physiol. Zool. 69, 618-634.

25. Laska, M. (1990) Food transit times and carbohydrate use in three phyllostomid bat species. $Z$. Säugertierk. 55, 49-54. 
26. Madkour, G. A., Hammouda, E. M., Ibrahim, J. G. (1982) Histology of the alimentary tract of two common Egyptian bats. Ann. Zool. (Agra) 19, 53-73.

27. Makanya, A. N. (1997) The morphology of the intestine of the entomophagous longfingered bat, Miniopterus inflatus: mucosal topography and possible landmarks. Acta Biol. Hung. 48, 15-27.

28. Makanya, A. N., Maina, J. N. (1994) Morphology of the alimentary tract of the insectivorous Horseshoe bat, Rhinolophus hildebradti, Peters: a scanning and light microscopic study. Afr. J. Ecol. $32,158-168$.

29. Makanya, A. N., Mayhew, T. M., Maina, J. N. (1995) Stereological methods for estimating the functional surfaces in the chiropteran small intestine. J. Anat. 187, 361-368.

30. Makanya, A. N., Maina, J. N., Mayhew, T. M., Tschanz, S. A., Burri, P. H. (1997) A stereological comparison of villous and microvillous surfaces in small intestines of frugivorous and entomophagous bats: species inter-individual and craniocaudal differences. J. Exp. Biol. 200, 2415-2423.

31. Manley, D. B., Williams, L. M. (1979) Structure of the gastrointestinal tract of the flying fox, Pteropus poliocephalus. J. Anat. 128, 649-650.

32. Marsh, M. N. (1971) Digestive-absorptive functions of the enterocyte. Ann. R. Coll. Surg. Engl. 48, 356-68.

33. Marshall, A. G. (1983) Bats, flowers and fruit: evolutionary relationships in the Old World. Biol. J. Linn. Soc. 20, 115-135.

34. Mayhew, T. M. (1990) Striated brush border of intestinal absorptive epithelial cells: stereological studies on microvillous morphology in different adaptive states. J. Electron. Microsc. Techn. 16, $45-55$.

35. Mayhew, T. M. (1996) Adaptive remodelling of the intestinal epithelium assessed using stereology: correlation of single cell and whole organ data. Histol. Histopathol. 11, 729-741.

36. Morrison, D. W. (1980) Efficiency of food utilization by fruit bats. Oecologia 45, 270-273.

37. Nelson, J. E. (1965) Movement of Australian flying foxes (Pteropodidae: Megachiroptera). Aust. J. Zool. 13, 53-73.

38. Ogunbiyi, O. A., Okon, E. E. (1976) Studies of the digestive enzymes of the African fruit bat, Eidolon helvum (Kerr). Comp. Biochem. Physiol. 55A, 359-361.

39. Okon, E. E. (1977) Functional anatomy of the alimentary canal in the fruit bat, Eidolon helvum and the insect bat, Tadarida nigeriae. Acta Zool. (Stockholm) 58, 83-93.

40. Oschman, J. L. (1978) Morphological correlates of transport. In: Giebisch, G., Tosteson, D. C., Ussing, H. H. (eds) Membrane transport in biology, Vol. III. Springer Verlag, Berlin, pp. 55-93.

41. Pfaller, W. (1982) Structure function correlation on rat kidney. Adv. Anat. Embryol. Cell Biol. 70, $1-106$.

42. Ratcliffe, F. (1932). Notes on fruit bats (Pteropus spp.) of Australia. J. Anim. Ecol. 1, 32-57.

43. Rosevar, D. R. (1965) The bats of West Africa. British Museum Nat. Hist., London.

44. Rhodin, J. A. G. (1974) Histology: A Text and Atlas. Oxford University Press, London, pp. 553-568.

45. Shilton, L. A., Altringham, J. D., Compton, S. G., Whittaker, R. J. (1999) Old World fruit bats can be long distance seed dispersers through extended retention of viable seeds in the gut. Proc. R. Soc. Lond. B266, 219-223.

46. Snipes, R. L., Snipes, H. (1997) Quantitative investigation of the intestines in eight species of domestic mammals. Z. Säugertierk. 62, 359-371.

47. Spring, K. R. (1998) Routes and mechanism of fluid transport by epithelia. Ann. Rev. Physiol. 60, $105-119$.

48. Stevens, C. E., Hume, I. D. (1998) Contributions of microbes in vertebrate gastrointestinal tract to production and conservation of nutrients. Physiol. Rev. 78, 394-427.

49. Tedman, R. A., Hall, L. S. (1982) The morphology of the gastrointestinal tract of the fruit bats, Pteropus alecto and Pteropus Poliocephalus (Megachiroptera). Bull. Aust. Mammal. Soc. 7, 58.

50. Tedman, R. A., Hall, L. S. (1985) The morphology of the gastrointestinal tract and food transit times in the fruit bats, Pteropus alecto and Pteropus poliocephalus (Megachiroptera). Aust. J. Zool. 33, $625-640$. 
51. Tisher, C. C., Madsen, K. M. (1991) The anatomy of the kidney. In: Brenner, B. M., Rector, F. C. Jr (eds.) The kidney, 4th edn. WB Saunders Co, Philadelphia, pp. 1-75.

52. van der Pijl, L. (1956) Remarks on pollination by bats in the genera Freycinetia, Duabanga and Haplophragma, and on chirepterophily in general. Acta Bot. Neerl. 5, 135-144.

53. van der Pijl, L. (1957) The dispersal of plants by bats (chirepterochory). Acta Bot. Neerl. 6, 291-315.

54. Wickler, W., Seibt, U. (1976) Field studies of the African fruit bat, Epomophorus wahlbergi (Sundevall) with special reference to male calling. Z. Tierpsychol. 26, 726-736.

55. Wilson, D. E. (1988) Maintaining captive bats. In: Kunz, T. H. (ed.) Ecological and behavioural methods for the study of bats. Smithsonian Institution Press, Washington DC, pp. 247-261.

56. Wolton, R. J., Arak, P., Godfray, H. C. J., Wilson, R. P. (1982) Ecological and behavioural studies of the megachiroptera at Mount Limba, Liberia, with notes on microchiroptera. Mammalia 46, 419-448.

57. Wrong, O. M., Edmonds, C. J., Chadwick, V. S. (1981) The Large Intestine: its role in mammalian nutrition and homeostasis. MTP Press Ltd, Lancaster.

58. Yalden, D. W., Morris, P. A. (1975) The Lives of Bats. The New York Times Book Co., New York, $247 \mathrm{pp}$.

59. Yeagle, P. (1987) The membranes of cells. Academic Press Inc., San Diego. 
